\title{
NOTAS SOBRE AS REPRESENTAÇÕES DO “FEMININO" NAS PÁGINAS DA REVISTA BRASIL-OESTE.
}

\author{
Notes about the REPRESENTATIONS OF THE "FEMININE" ON THE PAGES OF \\ BRASIL-OESTE MAgaZINE.
}

\author{
Eduardo de Melo Salgueiro* \\ eduardomsalgueiro@gmail.com
}

RESUMO: Neste texto pretendo mostrar como foram apresentadas as mulheres e a sua "feminilidade" nas páginas da revista Brasil-Oeste, mensário que circulou entre o período de 1956 e 1967. Farei uma breve consideração sobre duas colunas publicadas naquele periódico intituladas "Arte Culinária" e "Lar e Família" e que tinham como público-alvo, as mulheres. Neste sentido, minha intenção principal será problematizar algumas notas sobre as representações emitidas pela RBO, órgão de imprensa conservador, sobre a mulher e seu "papel" na sociedade, mais especificamente, no lar.

PALAVRAS-CHAVE: Mulheres, representações, revista Brasil-Oeste

ABSTRACT: In this paper I intent do show how women were presented and their "femininity" on the pages of Brasil-Oeste magazine, which circulated monthly between the period of 1956 and 1967. I will make a brief consideration about two columns published in that periodical titled "Arte Culinária" and "Lar e Família" (Home and Family) and that had as target audience, the women. In this way, my main intention is to present some notes about the representations emitted by the

* Professor da Universidade Federal do Sul e Sudeste do Pará (UNIFESSPA). Mestre em História pela Universidade Federal da Grande Dourados (UFGD) e doutorando pela mesma instituição 
Brasil-Oeste, conservative press media, about the woman and her "role" in society, more specifically, at home.

KEYWORDS: Women, representations, Brasil-Oeste magazine.

INTRODUÇÃO

Neste artigo, pretendo fazer algumas considerações de caráter introdutório sobre representações "do feminino" nas páginas da revista Brasil-Oeste ${ }^{1}$, mensário que circulou entre os anos de 1956 e 1967. ${ }^{2}$ Não será meu objetivo analisar mais profundamente o tema, mas tão somente apresentar tal questão. Portanto, problematizarei alguns textos publicados em duas colunas daquele periódico, intituladas "Arte Culinária" e "Lar e Família" e que tinham como público-alvo, as mulheres.

As pesquisas que estudam relações de gênero e história das mulheres no Brasil se desenvolveram consideravelmente a partir dos anos de 1980. Se antes disso já existiam trabalhos historiográficos sobre as mulheres, será ao longo desse período que "floresce um conjunto de estudos preocupados em revelar a presença das mulheres atuando na vida social, reinventando seu cotidiano, criando estratégias informais de sobrevivência", em síntese, confere-se "um destaque particular à sua atuação como sujeito histórico" (Rago, 1995:81).

Abstendo-me de mencionar maiores detalhes acerca da produção acadêmica brasileira sobre os estudos de gênero e história das mulheres, limito-me a destacar que há um considerável avanço nas pesquisas históricas sobre tal campo no interior das Ciências Humanas, pois como diz Michelle Perrot, hoje, "uma história 'sem as mulheres' parece impossível" (2007:13). É válido lembrar que a emergência das mulheres/relações de gênero nos estudos históricos foi tanto fruto de uma renovação temática dentro da própria disciplina, quanto das pressões externas, sobretudo após Hist. R., Goiânia, v. 19, n. 2, 2014 
o boom dos movimentos sociais engajados e da revolução cultural pós1960, que definitivamente influenciaram não só nos modos e costumes, mas também o campo da historiografia, e num plano mais alargado, dentro do próprio conhecimento científico. Como ressalta Margareth Rago,

O feminismo não apenas tem produzido uma crítica contundente ao modo dominante de produção do conhecimento científico, como também propõe um modo alternativo de operação e articulação nesta esfera. Além disso, se considerarmos que as mulheres trazem uma experiência histórica e cultural diferenciada da masculina (...) é inegável que uma profunda mutação vem se processando, também na produção do conhecimento científico (RAGO, 1998, p. 23-24).

Há, portanto, um alargamento da ideia de sujeito-histórico. Deste modo, o movimento feminista veio a ser um importante componente também no conhecimento científico, pois ajudou a renová-lo. No mesmo sentido, João Arriscado Nunes credita às novas perspectivas abertas pelas feministas uma importante contribuição para o conhecimento, especialmente no que diz respeito ao debate em torno da "desnaturalização e problematização da 'masculinização' histórica dos mundos da ciência, sustentada por instituições, práticas e ideologias profissionais". Além disso, prossegue o autor ressaltando que outro aspecto essencial da crítica feminista reside no fato de que ela pretende "contribuir para uma transformação da ciência existente, prolongando e renovando o horizonte crítico que esteve na origem da ciência moderna, incorporando novas interrogações, perspectivas, temas e práticas, em contextos institucionais e profissionais renovados" (2006, p. 69-70).

Outro tributo que devemos prestar à epistemologia feminista e aos estudos de gênero reside na questão da desnaturalização dos "papeis" do masculino e feminino. Ainda nas palavras de Nunes, diversas áreas, dentre elas, a antropologia, a biologia, a história e a sociologia foram as que mais incorporaram as interrogações e perspectivas críticas de inspiração feminista (Cf. 2006). No campo da historiografia, por exemplo, além de inicialmente ter 
buscado "trazer" as mulheres para a história como novos sujeitos históricos, outra questão parece ter sido crucial, isto é, "o reconhecimento de que a condição feminina é constituída histórica e socialmente" (BASSANEZI, 2009, p. 160), fugindo, portanto, do determinismo biológico.

No plano epistemológico há um encontro entre a perspectiva feminista e concepções do pensamento pós-moderno, uma vez que também a chamada virada linguística "que nos anos de 1960 deixaria raízes profundas, tornou a 'linguagem' e a 'cultura' os aspectos centrais para o entendimento [...] das sociedades do passado e do presente" (ROIZ, 2012), além de fazerem questionamentos à concepção moderna de ciência, ao marxismo, estruturalismo e às grandes metanarrativas que nortearam o discurso científico até meados do século XX. Assim, segundo Rago, a crítica feminista denuncia alguns aspectos do modo "moderno" de fazer ciência, uma vez que seu caráter particularista, ideológico racista e sexista: o saber ocidental opera no interior da lógica da identidade, valendo-se de categorias reflexivas capazes de pensar a diferença. Em outras palavras, atacam as feministas os conceitos com que trabalham as Ciências Humanas que são identitários e, portanto, excludentes. Pensa-se a partir de um conceito universal de homem, que remete ao branco-heterossexualcivilizado-do-Primeiro-Mundo, deixando-se de lado todos aqueles que escapam deste modelo de referência (RAGO, 1998, p. 25).

Neste sentido, é capital o uso do conceito de gênero articulado por Joan Scott quando se pensa em fazer uma história das relações de poder entre os gêneros. Não se trata, deste modo, apenas dar visibilidade aos novos sujeitos - incluindo a mulher - nas discussões das Ciências Humanas, mas revelar como, com o decorrer do tempo, todas/os fomos de certo modo moldadas/os por discursos que pretendem nos fazer crer que as coisas são "naturais", não nos permitindo perceber que o corpo é também lugar de dominação, que não se pode mais ponderar um pensamento científico que não almeje perceber o poder que existe também nas relações de gênero. 
Precisa-se, assim, entender as mulheres e os homens no curso da história a partir das relações de poder que se dão entre eles e uma das alternativas para resolver tal questão foi elaborada por Scott, ao conceituar a palavra "gênero". Diz ela que

(...) a criação inteiramente social das ideias sobre os papéis adequados aos homens è̀s mulheres. Trata-se de uma forma de se referir às origens exclusivamente sociais das identidades subjetivas dos homens e das mulheres. "Gênero" é, segundo esta definição, uma categoria social imposta sobre o corpo sexuado. Com a proliferação dos estudos sobre sexo e sexualidade, "gênero" tornou-se uma palavra particularmente útil, pois oferece um meio de distinguir a prática sexual dos papéis sexuais atribuídos às mulheres e aos homens (SCOTT, 1995, p. 14).

$\mathrm{Na}$ opinião de Raquel Soihet, a concepção de gênero elaborada por Joan Scott permite que seja possível enfatizar o "caráter fundamentalmente social, cultural, das distinções entre mulheres e homens, afastando o fantasma da naturalização" (PIMENTA, 2007, p. 161). Assim, nunca é demais ressaltar que tal como o sujeito "homem" universal não parece mais ser aceitável, faz-se necessário estarmos sempre alertas para as construções discursivas que nos induzem a acreditar que as coisas são "naturais", "essencialistas" ou que existe, por exemplo, uma "natureza" tipicamente feminina, isto é, um sujeito feminino universal. O que é essencialmente importante para as/os historiadoras/es é "identificar, para cada configuração histórica, os mecanismos que enunciam e representam como 'natural', portanto, biológica, a divisão social e [...] histórica, dos papéis e das funções" (CHARTIER, 1995, p. 42) do masculino e do feminino.

Desta maneira, a partir da $R B O$, pretendo aquilatar como a imprensa é um dos lugares mais importantes quando se busca entender como alguns grupos aspiram exercer sobre outros, determinadas visões do mundo. Em outras palavras, mostrarei de que modo a mulher ali referenciada pode ser um indicativo de um padrão/perfil/condição feminina criada ou idealizada em torno da redação daquele periódico e expressa em suas páginas. 


\section{A REVISTA E SUA CONIUNTURA}

A $R B O$ foi um mensário produzido no estado de São Paulo sob a direção dos jornalistas Fausto Vieira de Campos e, seu filho, Fausto M. G. V. de Campos $^{3}$. De modo resumido, pode-se dizer que sua linha editorial dedicava-se a difundir reportagens e artigos que abrangessem o mundo dos negócios agropastoris, direcionando seu olhar para a região oeste do Brasil (especialmente o estado de Mato Grosso), por meio de anúncios e informações sobre a política e economia. Neste sentido, ela se enquadrava no segmento temático agronômico da imprensa brasileira.

Importante assinalar que no interregno que se inicia com o fim da Era Vargas (1945) e que vai até o ano de 1964 (quando ocorre o Golpe Militar), o contexto nacional está, à época, passando por uma série de transformações, sobretudo em relação ao forte desenvolvimento econômico, o êxodo rural - desencadeando em um notável crescimento demográfico urbano -, forte industrialização, dentre outros aspectos. Como ressaltam diversos estudiosos, ${ }^{4}$ a década de 1950 (especialmente) é considerada como um período peculiar também na trajetória do jornalismo brasileiro, pois, de acordo "com o espírito do tempo dos anos JK, em que desenvolvimentismo e modernização são palavras de ordem, também os jornais diários (e o crescente mercado revisteiro) apressavam-se em se transformar" (BARBOSA, 2007, p. 149).

Dentre os vários segmentos da crescente "nova imprensa brasileira", mais profissionalizada e com um modelo de gestão mais próximo do empresarial, é válido dizer que desde a aurora da vigésima centúria, o segmento agronômico estava entre aqueles com maior projeção. Ana Luiza Martins indica que no final do século XIX houve uma crise no setor cafeeiro que acabou por desencadear a "baixa cotação internacional do produto, desarticulando fortunas, propriedades e trabalhadores do campo". O "lavrador brasileiro lidava com técnicas primitivas do amanho do solo e Hist. R., Goiânia, v. 19, n. 2, 2014 
cultivo dos produtos da terra" e "mesmo o cafeicultor paulista, tido como inovador na mecanização agrícola, mostrava-se refratário a aplicações econômicas que qualificassem e potencializassem seus negócios" (2008, p. 282). Esse homem do campo viu-se obrigado a buscar mais informações de mercado e essa "necessidade [...] justificava o investimento no periodismo agrícola". Assim, exigia-se "um proprietário mais informado e atento, capaz de gerenciar mão de obra competitiva, vendas diretas de café aos escritórios estrangeiros, mecanismos para fornecimento de crédito, otimização da produção" (Idem, p. 283-384).

Por consequência disso, o segmento agronômico, inicialmente modesto, com características de folhetos e boletins, cresceu na ordem de títulos 47,8\% entre os anos de 1912-1930, principalmente, porque "o agricultor de médio porte passou a ser também um leitor, engrossando o público consumidor, transformando o setor agrícola em filão comercial dos mais atraentes para investimentos, contemplando de anúncios de implementos agrícolas à necessária orientação técnica sobre produtos do campo" (MARTINS, 2003, p. 67).

Portanto, já na década de 1950 consolidava-se definitivamente na imprensa brasileira o ramo das revistas especializadas, e, adiciona-se a isso o fato de que também se ampliavam os debates sobre o desenvolvimento do país, econômica e estruturalmente, o que significa dizer que até os mensários com segmentação específica debatiam temas diversos, uma vez que isso permitia o aumento de anunciantes de vários setores, pois os investimentos da publicidade aumentavam e se diversificavam consideravelmente (ABREU, 1996, p. 16). No caso específico das revistas agronômicas, a política e a economia eram temas profundamente ligados às questões do campo. Assim, aproveitando-se do crescente desenvolvimento da propaganda, tal modalidade de produção jornalística tornou-se um veículo "publicitário dos mais efetivos", pois foi "através da porta do periodismo agrícola que se deu 
parte da colocação de produtos norte-americanos no Brasil, de utilidades domésticas a implementos agrícolas", uma vez que o periódico de tendência agrícola informava também "balanços e avaliações do comércio e indústria" (MARTINS, 2008, p. 301, os grifos são meus).

Levando isso em consideração, o mercado revisteiro agronômico foi um importante aliado para o setor da publicidade e propaganda em um momento em que o mercado de bens duráveis no Brasil desenvolvia-se em passo acelerado, sobretudo após o governo JK, com a implementação de fábricas de automóveis e facilidades que atraíram empresas dos mais diversos setores do mercado de consumo.

Assim, a questão que se coloca aqui é a seguinte: como uma revista agronômica, com debates voltados para a economia e política direcionados essencialmente para o público masculino - e com um objetivo muito claro de mostrar para os investidores brasileiros e estrangeiros o potencial existente nos lados do oeste do Brasil, tratou de inserir as mulheres em suas páginas ${ }^{5}$ Como eram retratadas? Quais eram os temas ali abordados? Estavam em consonância com outras revistas do mesmo segmento? Perguntas que não poderão ser totalmente respondidas neste texto, mas que servem para mostrar que existe um campo a ser pesquisado nos estudos de gênero nas páginas de revistas mais conservadoras, do tipo agronômico, tal como foi o caso da RBO.

"A MULHER" NA RBO: ASPECTOS GERAIS

Como já foi mencionado, a RBO circulou por doze anos, entre as décadas de 1950 e 1960, período no qual germinava o surgimento de movimentos sociais, dentre eles o feminista, no Brasil e no mundo. ${ }^{6} \mathrm{Em}$ síntese, dentre as principais características da mulher retratada naquele mensário, foi muito forte as representações dela como mãe, esposa e dona- 
de-casa. ${ }^{7}$ Os temas ali abordados eram aqueles ligados à felicidade conjugal (tais como, os bons modos na casa, a boa cozinha, a educação dos filhos, o respeito ao marido) além de tópicos relacionados à moda e à beleza.

Importante ressaltar que houve uma fragmentação no mercado jornalístico no decorrer do século XX, incluindo, claro, o ramo revisteiro. Tania R. de Luca assevera que, com a dimensão mais empresarial da imprensa por volta dos anos de 1950, as publicações dirigidas ao público feminino firmaram-se como um segmento altamente lucrativo (2012, p. 457), ainda que abordando assuntos "tipicamente" femininos, tendo a moda como tema central. Já naquele momento, é sabido que havia um considerável número de periódicos criados por mulheres e/ou com participação das mesmas desde o alvorecer do século XX (HAHNER, 1981). Nas seções dedicadas ao público feminino, a maior parte dos textos era efetivamente redigida por mulheres, o que parece ter sido uma tendência que havia se iniciado desde o crepúsculo do século XIX, pois como informa Ana Luiza Martins, naquele período já brotava uma mudança no que tange ao consumo, a produção e mudança do lugar das mulheres na imprensa brasileira. Diz a autora que "de leitora de folhetins e/ou romances, editados em in $8^{\circ}$, formato apropriado para as 'diáfanas mãos femininas', (as mulheres) passaram respectivamente a colaboradoras e produtoras de revistas" (2008, p. 372, os grifos são meus).

Como será mostrado nas páginas a seguir, havia certa consonância dos textos publicados na RBO - mesmo sendo de segmento agronômico - em relação às revistas direcionadas ao público feminino da época, que abordavam como um dos temas principais a felicidade conjugal, ou a vida em família. Segundo Carla Bassanezi, tais questões se faziam importantes e circulavam na imprensa, pois como informa a autora (que analisou o ideal de felicidade nas revistas Claudia e Jornal das Moças), o amor entre os cônjuges era considerado um ingrediente importante, mas não o suficiente para garantir um 'casamento harmonioso', e as revistas direcionadas às mulheres 
buscavam apresentar receitas prontas para o algo mais que sustentava os matrimônios dentro do ideal de felicidade proposto como único e universal (1993, p. 112, os grifos são meus). Tal discurso, também era fortemente impresso nas páginas da $R B O$.

Ainda nas palavras de Bassanezi, os referidos meios de comunicação por ela estudados, que abarcavam os anos de 1945-1964, tinham como objetivo atingir principalmente as mulheres leitoras de classe média e do segmento urbano. Já no caso da $R B O$, seu público-alvo era efetivamente os "homens de negócios". Levando isso em consideração, acredito que as mulheres leitoras daquele mensário eram igualmente da classe-média ou dos segmentos mais abastados da sociedade, abarcando tanto as que viviam no campo, quanto àquelas que residiam na cidade. Ainda que fosse um periódico de segmento agronômico, a RBO também buscava atrair investidores da indústria, além de inserir temas fortemente ligados à política regional e nacional, o que significa dizer que ela tinha forte circulação urbana.

O projeto editorial de Fausto Vieira de Campos justificava-se por meio de um discurso que se preocupava em apontar e discutir os principais problemas de diversos segmentos que impediam o estado de Mato Grosso (e a região oeste do Brasil) de prosperar, dada a ausência de um veículo de comunicação que pudesse fazer chegar aos mais altos escalões da política e dos setores da economia do país o "grito de socorro" mato-grossense.

Em meados do século XX, não havia no estado de Mato Grosso uma revista similar à $R B O .^{8} \mathrm{O}$ valor simbólico daquela publicação era um ingrediente especial, uma vez que os seus objetivos demonstravam um forte teor de "paixão" por aquela região. Deste modo, aquele mensário era uma possibilidade encarada pelos seus idealizadores como "ideal" e apto a alocar Mato Grosso e o centro-oeste do Brasil no lugar que mereciam estar, isto é, "no rumo do desenvolvimento econômico". É por meio da palavra escrita 
que tal projeto vai se ilustrar na construção constante de uma série de ideais para aquela conjuntura, fossem eles econômicos, políticos e, por que não, de relações de gênero.

Feitas estas considerações, é notório que se tratava de uma "revista de negócios" políticos e econômicos. Não por acaso a mulher ficou de fora de qualquer atenção nos seus primeiros dezenove números, quando surgia, no mês de dezembro de 1957, $n^{\circ} 20$, a seção de receitas Arte Culinária (publicada mensalmente até a edição $\mathrm{n}^{\circ} 55$ ) e substituída, a partir de fevereiro de 1961 ( $n^{\circ} 56$ ), pela coluna Lar e Família, quando se tornou possível alargar o leque de assuntos abordados, e assim ficou até o $n^{\circ} 117$ (correspondente aos meses de agosto e setembro de 1966), pouco antes da extinção da revista.

Logo abaixo apresento um pequeno quadro que permite visualizar melhor o surgimento das seções dedicadas às mulheres:

\section{QUADRO 1}

Seções dedicadas ao público feminino

\begin{tabular}{|c|c|c|c|}
\hline Nome da Seção & Temática & Duração & Responsável \\
\hline Arte Culinária & Receitas culinárias. & Do $n^{\circ} 20$ ao $n^{\circ} 23$ & Regina Moraes \\
\hline Arte Culinária & Receitas culinárias. & Do $n^{\circ} 25$ ao $n^{\circ} 55$ & Teresa Umbelina \\
\hline Lar e Família & $\begin{array}{c}\text { Culinária, costumes, } \\
\text { família. }\end{array}$ & Do $n^{\circ} 56$ ao $n^{\circ} 59$ & Teresa Umbelina \\
\hline Lar e Família & $\begin{array}{c}\text { Culinária, costumes, } \\
\text { família. }\end{array}$ & Do $n^{\circ} 60$ ao $n^{\circ} 93$ & Diversos autores/as \\
\hline Lar e Família & $\begin{array}{c}\text { Culinária, costumes, } \\
\text { família. }\end{array}$ & Do nº 94 ao $n^{\circ} 117$ & $\begin{array}{c}\text { Ednice Normanha } \\
\text { Bardauil }\end{array}$ \\
\hline
\end{tabular}

A partir do que foi exposto no quadro acima, um aspecto a considerar diz respeito à durabilidade daquelas seções, pois ainda que nenhum tema relacionado às mulheres tivesse sido abordado antes da 
vigésima edição da revista, se somarmos a Arte Culinária com a Lar e Família, ambas figuraram em noventa e quatro, dos cento e vinte e três números que compõem a coleção da $R B O$, situando-se entre as que mais permaneceram ativas na história daquele mensário. Este não é um dado qualquer, pois pode ser um indício ou traduzir uma possível demanda de um público feminino, ou, como assinala Chartier (1999), de uma "comunidade de leitores(as)", na qual pertence um conjunto de pessoas que partilham de interesses por determinados assuntos.

Creio que a própria mudança de temas (inicialmente voltados apenas às receitas culinárias, e depois com abordagem mais abrangente), já é um forte indicador de uma pressão de leitoras em potencial que se sentiam pouco contempladas com apenas uma ou duas páginas de pratos culinários na seção Arte Culinária. Isso significa dizer que "o texto, o objecto que the serve de suporte e a prática que dele se apodera" (Chartier, 1990, p. 127) são três aspectos que não podem ser negligenciados quando se faz uma análise tal como a que suscito na presente abordagem, pois, "um texto, só existe se houver um leitor para lhe dar um significado" (Chartier, 1999, p. 11).

A princípio, é bom que se diga que tal "pressão" por parte das leitoras que vislumbro aqui não se fazia diretamente e literalmente presente nas páginas da revista, o que não significa dizer que ela não existia. De qualquer maneira, mostrarei a seguir algo que julgo ser um importante componente para compreendermos melhor a relação ou o tratamento dado pela direção da revista ao público feminino. Trata-se de mostrar a porcentagem das cartas publicadas pela revista na seção Cartas da redação, que foram enviadas por mulheres.

Dentre o total dos cento e vinte e três exemplares publicados, a seção Cartas da redação esteve presente em quarenta e quatro deles, sendo divulgadas cento e sessenta e quatro cartas das/dos leitoras/es. No 
quadro abaixo exponho o percentual das missivas publicadas na revista pelos públicos masculino e feminino:

\section{QUADRO 2}

Cartas publicadas pela revista

\begin{tabular}{ccc} 
Sexo & Número de cartas & $\%$ \\
\hline Homens & 124 & 75,6 \\
\hline Mulheres & 03 & 1,8 \\
\hline Outros* $^{*}$ & 37 & 22,5 \\
\hline TOTAL & 164 & 100 \\
\hline
\end{tabular}

*Empresas particulares, associações rurais, órgãos oficiais do poder público.

A maioria das cartas publicadas tinha como tema central os aspectos positivos da RBO. Os diretores do mensário utilizavam muito bem a tática de dar "voz" aos seus leitores, pois o conteúdo ali publicado, na maioria das vezes, era de elogios ou de dúvidas, solicitando por informações diversas, desde negócios agropecuários até à procura de assinaturas de exemplares da revista. Como informa Letícia Moraes, todo jornal (ou revista) precisa de leitores que se identifiquem com seus interesses para lhes dar legitimidade (2001. p. 8). Assim, certamente a seção de cartas da $R B O$ foi um lugar privilegiado para efetivar esse procedimento.

No entanto, como se pôde perceber, a participação da mulher nas cartas publicadas pela revista foi praticamente inexistente, indicando uma abissal diferença entre homens (maioria) e mulheres (minoria) que tinham suas missivas divulgadas. Há aí uma contradição, pois mesmo que o mensário contasse com seções com tamanha longevidade como foi o caso daquelas voltadas ao público feminino, as cartas das leitoras raramente eram impressas em suas páginas.

Tal negligência pode ser interpretada de três maneiras. A primeira delas seria aquela em que a direção da revista simplesmente não se interessava em publicar as missivas enviadas pelas mulheres. Uma segunda 
possibilidade pode residir no fato de que realmente era ínfimo o número de cartas enviadas por aquele público (o que abalaria, em princípio, minha tese inicial segundo a qual existiria uma pressão por parte das leitoras). A última interpretação que pode ser levantada pode ter relação com o fato de que a revista não costumava publicar textos de leitoras/es que a criticavam. ${ }^{9}$ Assim, não seria surpresa alguma se tal negligência fosse uma resposta às possíveis críticas existentes nas cartas em relação às seções Arte Culinária e Lar e Família. São dúvidas que lamentavelmente não posso responder, mas que lanço para que se possa refletir a respeito ou eventuais futuras/ os pesquisadoras/es possam nos responder. Tais questões poderiam ser respondidas caso houvesse acesso às correspondências enviadas pelas/os leitoras/es em um possível arquivo particular da família Campos, no entanto, em conversa com Fausto M. G. de Campos, ele me informou que não existe mais nada arquivado em relação à extinta $R B O$.

Mas como era efetivamente o espaço dedicado às mulheres nas páginas da revista? Qual era o perfil das pessoas que publicavam ali? Inicialmente, quem esteve à frente da seção Arte Culinária foi Regina Moraes, apresentada naquela ocasião como "Nutricionista-Chefe da Companhia Swift do Brasil S.A". Ao lado do seu nome, na parte superior direita da página, havia uma ilustração que indicava uma representação da mulher como dona-decasa. Tal representação consiste em mostrar uma figura feminina dedicada aos serviços culinários, utilizando trajes característicos dessa atividade, como o avental e o vestido, "representando" sua "feminilidade".

Uma primeira constatação merece destaque em relação a essa coluna. A representação imagética feminina. A mulher usa avental, está sempre sorrindo e aparenta sentir-se bem no papel que the é atribuído, isto é, o da dona-de-casa que deve cozinhar para sua família. ${ }^{10}$ No texto que introduz as receitas culinárias isso fica muito claro, como mostrarei a seguir, a partir de um pequeno fragmento retirado dele: 
Não se aborreça, minha amiga, se as crianças recusarem a sopinha de verduras que você costuma dar-Ihes. Elas têm razão! Com êste calor, sopa quente? Mude logo seu cardápio, de acôrdo com a estação do ano e ofereça à sua família uma das deliciosas sopinhas que lhe estou sugerindo abaixo. Verá que todos comerão com redobrado apetite e pedirão "bis" (RBO, janeiro de 1958, $\mathrm{n}^{\circ} 21$, p. 28). ${ }^{11}$

Como ficou claro, tratavam-se de receitas voltadas diretamente à mãe/dona-de-casa. Os discursos - imagético e textual - que emanavam das páginas da $R B O$ eram muito comuns na época (inclusive em revistas direcionadas ao público feminino, por exemplo), isto é, aqueles que posicionavam a mulher no campo da passividade e da submissão, ainda que a apresentasse com um belo sorriso no rosto.

É válido dizer, no entanto, que desde o pós-guerra a imagem da mulher vinha sendo construída, na Europa e nos Estados Unidos, de modo ambivalente, pois ao mesmo tempo em que lhe era dado apenas o espaço privado (como mãe e esposa), havia uma exploração (por parte do mercado cultural) de seu corpo mais erotizado e emancipado (PASSERINI, 2000, p. 381). Na $R B O$, não há este segundo aspecto, somente o primeiro se fez presente com muita regularidade e praticamente não se alterou durante todo o período em que Arte Culinária foi publicada. A esposa/mãe/dona-de-casa é retratada sempre com muita sutileza, o que é muito comum nas fotografias e desenhos publicados em revistas daquele período, pois tal imagem da mulher correspondia àquilo que era pregado pela Igreja, ensinado por médicos e juristas, legitimado pelo Estado e divulgado pela imprensa. Mais do que isso, tal representação acabou por recobrir o "ser mulher" - e a sua relação com as suas obrigações passou a ser medida e avaliada pelas prescrições do dever ser (MALUF; MOTT, 1998, p. 374).

Ainda que não tenha se modificado drasticamente nos anos em que foi publicada, Arte Culinária mudou de direção, ficando aos cuidados, duas edições mais tarde ( $n^{\circ} 22$, em fevereiro de 1958), de Maria Silveira 
(apresentada como "Chefe da Cozinha Royal"), que já participava daquela seção postando receitas culinárias, dividindo o espaço com Regina Moraes.

Levando em consideração a participação dessas duas mulheres, um dado merece ser assinalado e que é um indício da considerável importância que a seção feminina exerceu para a revista também no campo financeiro. Enquanto Regina Moraes esteve à frente de Arte Culinária, os anúncios da Companhia Swift do Brasil S.A. passaram a ser veiculados na página logo após as receitas culinárias. $\mathrm{O}$ mesmo pode ser dito no que diz respeito à Maria Silveira, representante dos produtos Royal, que também passou a ocupar espaço publicitário na revista após a sua inclusão, ocupando, inclusive, página inteira ao lado direito do suporte da revista, que é o mais adequado para anúncios publicitários, conforme informa Luzmara Ferreira:

a página da direita é privilegiada por seu aspecto físico, dada a maior mobilidade das páginas à esquerda do suporte, a direita, é a página na qual o leitor detém mais o olhar, por ser aquela que primeiro desvelase ao olhar leitor, ao virar de páginas, além de apresentar-se sem as ondulações características da página esquerda, que graças ao modo como as folhas são coladas impede que as mesmas se apresentem planas. Por se tratar de um lugar privilegiado da revista, a página da direita tornou-se um produto comercialmente mais caro (FERREIRA, 2003, p. 113).

Porém, a participação de Regina Moraes e Maria Silveira não passou da edição $n^{\circ} 24$, abril de 1958 . A partir do número seguinte, a seção Arte Culinária ficou sob os cuidados de Teresa Umbelina, que era filha de Fausto Vieira de Campos. Duas alterações especiais foram sentidas com a entrada da progênita de Campos. A primeira delas reside no âmbito da publicidade anexada àquela seção da revista e que sofreu considerável modificação, pois um número após Umbelina ter assumido a direção, um forte anunciador passou a compor um espaço considerável naquela coluna. Tratava-se da marca Maizena, que a partir de então passou a figurar em muitas edições, tornando-se o quarto maior anunciante de toda a coleção da 
$R B O$, estando atrás apenas de potências do mercado publicitário e industrial da época, tais como a Jeep (do setor automobilístico), e da Pfizer (fortíssima empresa do segmento agropecuário).

Como se sabe, todo pesquisador que toma uma publicação impressa periódica como fonte e objeto de análise, precisa levar o aspecto propaganda em consideração, pois muitas vezes apresentam elementos que em uma leitura mais apressada podem passar despercebidos, porque a publicidade e seus espaços indicam a articulação da publicação a determinados interesses empresariais e comerciais em uma dada conjuntura (CRUZ; PEIXOTO, 2007, p. 262). Neste sentido, além de uma provável demanda/pressão das leitoras, igualmente é bastante plausível supor que a presença da seção feminina trazia um profuso bônus financeiro para os cofres da Brasil-Oeste Editôra.

Com o passar dos anos, Arte Culinária foi retirada das páginas do mensário em favor de uma ampliação de assuntos abordados, com o surgimento da seção Lar e Família, ainda sob a direção de Teresa Umbelina (que ali permaneceu até maio de 1961 , edição $n^{\circ} 59$, não figurando mais como colaboradora da revista depois dessa data). Após da inauguração desse novo espaço, conforme mencionado, ampliaram-se os temas discutidos nele. A partir de então, questões que envolviam a família, tais como os modos, os costumes, a economia doméstica e a saúde passaram a ser debatidos. Entre o período que corresponde a abril de 1961 (edição n 60), a maio de 1964 (edição $n^{\circ}$ 93), diversas/os autoras/es e colunistas publicaram seus textos naquela coluna. Em relação às mulheres, foram elas, Neuza C. Macedo, Ecilda Cesconetto, Maria José Gerard, Teresa Noronha e Enilce C. Ribeiro. Um aspecto que merece destaque foi a presença de colaboradores homens que escreveram para aquela seção. Foram eles, o professor Valério Giuli, o advogado Célio de Arruda Camargo, e o médico Alcides Laffranchini. 
As mulheres tinham como principal característica redigir textos relacionados aos modos e costumes, já os três homens que ali participaram, escreviam textos com as seguintes características: o professor Giuli colaborava com artigos mais voltados à educação da família. Na sua condição de educador, seus escritos tinham como principal característica servir de auxílio aos pais no cuidado educacional para com as crianças. O médico Laffranchini, por sua vez, publicou escritos voltados às questões sobre a saúde, incluindo os cuidados com a alimentação. $\mathrm{O}$ advogado Camargo compunha textos mais técnicos e voltados aos temas do Direito da Família, buscando elucidar as/os leitoras/es no que tange a assuntos como, por exemplo, o desquite, a adoção, pensão alimentícia, dentre outros.

Levando em consideração tais informações, o que merece ser destacado reside no fato de que os assuntos "técnicos" eram escritos pelo punho masculino, enquanto aqueles mais voltados às questões do dia-a-dia, eram relegados à pena feminina. Isso me remete ao pensamento de Michelle Perrot, quando destaca que as mulheres (em determinados períodos da história) aparecem no espaço público, manifestando-se apenas "na qualidade de mães, de donas-de-casa, de guardiãs dos víveres" (2007, p. 21 ) e essa condição estava bem explícita nas páginas da $R B O$. Nos quadrantes da revista, o espaço dado a elas era muito restrito, isto é, havia um limite de tipo de texto ou discurso possível a ser enunciado. Conforme ressalta a historiadora francesa:

O uso da escrita pelas mulheres repousa sobre o seu grau de alfabetização e o tipo de escrita que Ihes é concedido. Inicialmente isoladas na escrita privada e familiar, autorizadas a formas específicas de escrita pública (educação, caridade, cozinha, etiqueta...) elas se apropriaram progressivamente de todos os campos da comunicação o jornalismo, por exemplo - e da criação: poesia, romance, sobretudo, 
história às vezes, ciência e filosofia mais dificilmente (PERROT, 2005, p. 13).

No caso em apreço, nenhum texto científico ou filosófico foi escrito pela caneta feminina. No entanto, ao que me parece, havia uma tendência, nos anos de 1950-1960, de as revistas agronômicas disporem espaços para o público feminino, ainda que com as limitações de assuntos abordados. Para exemplificar tal questão, Ecilda Cesconetto, uma das colaboradoras citadas da RBO, também escrevia para uma coluna de direcionamento similar à "Lar e Família" para a revista Mundo Agrícola. O título de tal seção era "Mundo Agrícola Feminino", na qual era publicada uma porção de temas muito semelhantes àqueles na $R B O$. Isto pode ser um indicativo de que havia, dentre os mensários de direcionamento agropecuário, um tipo de discurso produzido sobre e para as mulheres e que carece de uma pesquisa mais aprofundada.

Assim, se a partir do século XIX, conforme aponta Perrot, houve um acentuamento da "racionalidade harmoniosa [da] divisão sexual", que relegava a cada um dos sexos suas funções, seus papeis, seus espaços e seu lugar, em que para o homem - a ciência, a política e o espaço público -, enquanto que às mulheres - a economia doméstica e os cuidados com a família, encarregada do lar - (1992, p. 178), não parece exagero afirmar que ainda no século $X X$, tal discurso se fazia presente, mesmo que já houvesse consideráveis alterações, pois conforme assevera Bassanezi,

No modelo dominante de família na época enfocada, as distinções de gênero delegam aos homens autoridade e poder sobre as mulheres (...) As mulheres, por sua vez, são definidas a partir dos papéis femininos tradicionais (prioritariamente mães, donas de casa e esposas, vivendo em função do outro, o homem) das características consideradas "próprias das mulheres" englobadas no termo "feminilidade" (pureza, doçura, resignação, instinto materno, etc).

Ao mesmo tempo em que discriminações de gênero se manifestavam com intensidade, certas distâncias entre homens e mulheres se reduzem. O trabalho da mulher, ainda que cada vez mais comum, 
continua cercado de preconceitos e encarado como subsidiário ao trabalho do 'chefe da família', o homem (1993:113-114).12

É sabido que em meados de 1950 ainda era muito forte a presença de revistas que fortaleciam a ideia de "sujeito-mulher-ideal" traduzido pela concepção de mulher/mães/dona-de-casa. Assim, desde as décadas iniciais do século XX "o exercício das letras, em princípio condenado pela carga de iniciativa e questionamentos que comportava, foi tolerado e até consentido; mais ainda quando reiterava o tradicional papel feminino de mãe-esposa-rainha do lar" (MARTINS, 2008, p. 372, os grifos são da autora).

Pureza, doçura e instinto materno são três das qualidades essenciais para uma mulher, segundo os diversos textos difundidos na RBO. Para mencionar apenas um exemplo sobre tal questão, apresento o caso do artigo escrito por Maria José Gerard, intitulado de "Como deve a mulher concorrer para um mundo melhor". Escolho citar alguns fragmentos desse artigo, pois a autora pretendia indicar uma profissão, considerada ideal para as mulheres daquele período, conforme pode ser lido a seguir:

O caráter da criança é formado nos joelhos maternos. Na missão extraordinàriamente nobre e bela de ser mãe, a mulher contribui de forma decisiva para a melhoria da sociedade, fornecendo-lhe novos valores, cidadãos perfeitamente capazes de promoverem o progresso e a felicidade entre os homens ( $R B O$, julho de 1961, $\mathrm{n}^{\circ} 61, \mathrm{p}$. 29).

Do trecho citado acima, nota-se que a condição de mãe já teria o caráter missionário no sentido de formar bons cidadãos. A influência de uma maternidade "segura" e "eficaz" seria o pilar para que houvesse um "aperfeiçoamento das coletividades humanas". Entretanto, diz Gerard que o raio de ação social da mulher não deveria se restringir apenas ao ambiente da atividade doméstica, e uma profissão extremamente valorizada para a época era encarada pela autora como uma extensão da maternidade, isto é, o magistério, conforme é possível notar no seguinte trecho:

Pode e deve a mulher, por consequência, concorrer para a melhoria da sociedade humana, combatendo o egoísmo, praticando e ensinando 
os princípios da caridade e da solidariedade (...) incutindo em seus filhos os sentimentos de fraternidade e de justiça (...).

No magistério, especialmente no magistério primário, encontra a mulher outro vasto campo de aplicação dos seus predicados de coração, inteligência e cultura, no qual poderá prestar eficacíssimo concurso à formação de novos valores sociais ( $R B O$, julho de 1961, $\mathrm{n}^{\circ}$ 61 , p. 29, os grifos são meus).

Nota-se que a profissão de professora - sobretudo das séries iniciais -, era encarada efetivamente como uma extensão do papel de mãe. Por mais que já houvesse uma autonomização das mulheres naquele momento, fica nítida a concepção conservadora e tradicional do papel feminino. Um aspecto curioso a ser ressaltado reside no fato de que na fotografia que compõe o artigo acima citado, ao invés de retratar uma mulher em suas atividades no magistério (que estaria em consonância com as ideias do texto), evidenciava-se uma sorridente esposa/mãe/dona-de-casa que vê com brilho nos olhos o fraterno abraço de seu esposo e sua pequenina filha.

Em outra ocasião, na edição de $n^{\circ} 78$, mês de fevereiro de 1963, um artigo sem assinatura foi postado na seção "Lar e Família" sob o título, "A Família" e igualmente coloca o papel de mãe como central para o bom "crescimento" da formação moral da criança, como pode ser visto logo a seguir.

O ambiente familiar influi no crescimento e na formação moral e cívica da criança.

Ao adentrarmos uma casa, deveríamos encontrar sempre um casal unido, tanto no plano físico, como no moral. O pai seria um chefe de família zeloso pelo bem comum, enquanto que a espôsa seria o elemento doce e conciliador: a alma do lar. Haveria crianças dos dois sexos, em proporção equilibrada (...) e o mais velho seria de preferência menino (RBO, fevereiro de 1963, $\mathrm{n}^{\circ} 78, \mathrm{p} .45$, os grifos são meus).

Nota-se que há, de antemão, o estabelecimento de papeis a serem cumpridos pelo pai e pela mãe. Há na figura masculina a ideia de "chefe", e na figura feminina a essencialização tão comum em discursos mais 
conservadores, que atribuem à "natureza" da mulher características como a docilidade e a conciliação, ou o "coração" (alma) de um lar que pretende ser feliz. Conforme informam Gláucia Diniz e Luciana Santos,

Mulheres passaram a ser, sistematicamente, preparadas para serem mães esposas notáveis: elas foram convocadas a se dedicarem ao papel de "rainhas-do-lar". Ocorre, dessa forma, um movimento de idealização e valorização do exercício desse papel. Inseridas nesse modelo, mulheres foram aparentemente reconhecidas por seu desempenho no espaço privado. Uma família "perfeita" era produto do trabalho de uma esposa exemplar (2011, p. 139).

O fechamento do artigo em apreço é bastante esclarecedor em relação ao papel que a mulher deveria exercer para que não fosse perdida a harmonia do lar em um momento - já nos anos de 1960 -, em que se acentuavam algumas mudanças culturais de comportamento na sociedade ocidental, com movimentos reivindicatórios diversos, que procuravam fugir de padrões pré-estabelecidos. Diz o autor ou a autora do texto,

Se tôda família, ou se tôda mãe de família, procurasse viver dentro das imposições das leis naturais, seguindo os conselhos dos que acumularam experiência e graciosamente as legam aos mais novos, não existiria esta geração de insatisfeitos, de revoltados, que caracteriza os tempos hodiernos (RBO, fevereiro de $1963, n^{\circ} 78$, p. 45 , os grifos são meus).

A naturalização da função feminina no trecho acima citado fica bastante evidente. É como se fosse necessário - frente aos novos tempos que se aproximavam, de "revoltados" e "insatisfeitos" - que a mulher canalizasse suas forças acerca daquilo que "Ihe foi ensinado", avalizado pelas "imposições das leis naturais". A formação de bons filhos, honestos e educados passava diretamente pela função da esposa/ mãe/dona-de-casa. Havia, neste sentido, uma noção essencialista de mulher que a tratava como sujeito fixo, como se houvesse uma 
identidade feminina imutável e que precisava ser conservada para o bem-estar familiar e, por extensão, da sociedade de modo geral.

Assim, ao analisar a imprensa, é de fulcral importância termos consciência de que não existem textos neutros, pois deles emanam representações que possuem objetivos muito claros e os discursos ali produzidos têm por interesse "com suas repetições e constância de assuntos e idéias", intentar "moldar este público, formar gostos, opiniões e padrões de consumo e conduta" (BASSANEZI, 1993, p. 145). Conforme assevera Stuart Hall, a mídia tem como papel central construir - por meio da linguagem -, a realidade, isto é, os meios de comunicação pretendem definir e não simplesmente refletir sobre a "realidade". Há sempre uma intencionalidade:

Definições da realidade são sustentadas e produzidas através de todas aquelas práticas linguísticas (entendidas num sentido amplo) por meio das quais definições seletivas do 'real' são representadas. Mas representação é uma noção muito diferente daquela de reflexão. Implica o trabalho ativo de selecionar e apresentar, de estruturar e dar forma: não simplesmente de transmitir um significado já existente, mas o trabalho mais ativo de fazer as coisas significarem. É uma prática, uma produção de significado/sentido: o que subsequentemente vem a ser definido como uma 'prática significante'. A mídia/meios de comunicação são agentes significantes (Hall, 1982, p. 64, os grifos em itálico são do autor) ${ }^{13}$.

Portanto, há uma clara intenção em "dar forma", "estruturar" um tipo de "mulher-ideal" nas páginas da RBO, especialmente na seção "Lar e Família". Pureza, doçura e instinto materno são três das qualidades "essenciais" para uma mulher, segundo os diversos textos difundidos na revista. Por outro lado, não há como negligenciar que existe uma tentativa de corresponder a uma demanda, aos interesses e às aspirações de um público leitor ou de uma "comunidade de leitoras" (conforme já mencionei). É uma constante "luta" travada pelas imposições dos editores/diretores e as aspirações das/dos leitoras/es, que buscam por informações que lhes adicione conteúdo às suas vidas. 
Certa vez, na seção de cartas da edição de $n^{\circ}$ 57, março de 1961, uma leitora congratulava a direção da revista pela reformulação da então coluna Arte Culinária, naquela ocasião, recém transformada em Lar e Família. Dizia ela:

SRA. MARTHA CORRÊA ALVES (Belo Horizonte-MG) - “... congratulamonos com a revista BRASIL-OESTE pelo lançamento da nova seção LAR E FAMÍLIA, que veio preencher uma lacuna bastante sensível, pois que, além de meu marido e do pessoal da fazenda, que leem, com atenção, os artigos sôbre agricultura, pecuária e economia, há em nossa casa moças e senhoras, que agora encontram um material predileto para a leitura de todo mês. Parabéns." (RBO, março de 1961, n 57, p. 32, os grifos são meus, maiúsculas do original).

Acho pertinente destacar três aspectos a partir do relato dessa missiva: o primeiro reside no fato de que, segundo informa a remetente, o grupo de leitoras/es dos artigos destinados a falar sobre agricultura, pecuária e economia, era aquele em que pertencia o seu marido e o "pessoal da fazenda" (provavelmente os funcionários homens), indicando, mais uma vez que os textos técnicos/científicos/econômicos eram escritos por homens e direcionados exclusivamente a eles.

O segundo aspecto refere-se ao seguinte trecho: "há em nossa casa moças e senhoras, que agora encontram um material predileto para a leitura de todo mês", isto é, as mulheres da fazenda que se inclinavam especialmente pelos assuntos de "interesses femininos" e a coluna Lar e Família parecia suprir tal lacuna. Neste sentido, se havia um tipo de texto autorizado à escrita feminina, parece-me que o mesmo se pode dizer acerca dos escritos que poderiam ser lidos por elas.

O terceiro aspecto tem relação com o poder de seleção das cartas que eram publicadas, demonstrando o quanto os diretores da revista escolhiam cuidadosamente os trechos que os elogiavam, colocando, deste modo, as mulheres-leitoras em uma posição de "aparente" submissão. Submissão por pretender demonstrar - por meio do exemplo acima citado 
- que elas aceitavam alegra e passivamente aquilo que era publicado "para elas". Quando digo "aparente", indico e suponho que não retrata fielmente a recepção feminina da revista, uma vez que as leituras poderiam ser diversas e contraditórias.

Assim, remeto-me diretamente às palavras de Chartier, quando diz que "a construção da identidade feminina se enraíza na interiorização pelas mulheres, de normas enunciadas pelos discursos masculinos", ainda que "uma tal incorporação da dominação não exclui, entretanto, afastamentos e manipulações", pois para as mulheres, não resta somente a possibilidade de se curvarem "a uma submissão alienante, mas também construir um recurso permitindo deslocar ou subverter a relação de dominação" (Chartier, 1995, p. 40-41).

O que pretendo dizer, já em vias de conclusão (do artigo, que fique bem claro, não do tema, pois há muito a pesquisar), é que nas páginas da $R B O$, ainda que o discurso mais fortemente presente fosse aquele conservador, o próprio fato de ter havido uma seção destinada às mulheres, e que foi remodelada quando mudou de Arte Culinária para Lar e Família, já é um indicativo de que havia um grupo de leitoras em potencial que não poderia ser negligenciado.

Se nas edições entre o $n^{\circ} 20$ e 55, o espaço dado a elas era apenas aquele exclusivamente dedicado à cozinha, com o passar do tempo houve uma notável ampliação de foco, abordando assuntos que extrapolavam tal questão - mesmo que se restringissem, em sua maioria, a temas de ordem mais ligada a casa (ao privado). Porém, foram vários os anos em que a seção Lar e Família circulou, indicando a importância daquele espaço.

São muitos artigos, várias possibilidades e uma riquíssima fonte que merece um estudo mais profundo, sobretudo se for aumentado o escopo da análise no sentido de observar se haviam ou não seções semelhantes em outras revistas do segmento agronômico. Como pude mostrar, no mensário 
Mundo Agrícola isso ocorria e o discurso se aproximava muito àquele da $R B O$, tendo inclusive uma colaboradora em comum. Presumo que em outros periódicos do mesmo segmento, configuração semelhante possa ter existido.

Conforme informei no início do artigo, minha intenção aqui foi muito mais apresentar o problema do que "resolver" tal questão. Saber qual foi o comportamento de um órgão de imprensa conservador (notadamente presente no discurso da $R B O$ ), se posicionou em relação às mudanças nas relações de gênero pós1960/1950-, já é uma instigante abordagem a ser feita. Uma leitura mais precisa de todos os textos publicados em periódicos agronômicos pode elucidar as dúvidas aqui apresentadas.

NOTAS

(Endnotes)

1 Doravante, RBO.

2 A RBO lançou um total de 123 edições, circulou nacionalmente e produziu algo em torno de 1.500 .000 exemplares.

3 Inicialmente, a $R B O$ foi lançada de maneira independente, sem vínculo com nenhuma editora, contudo, a partir do segundo ano de circulação, passou a ser publicada pela BrasilOeste Editôra Ltda., administrada pelos jornalistas acima referenciados.

4 Ver: Abreu (1996); Barbosa (2007); Luca; Martins (2006); Ribeiro (2003).

5 Para ilustrar tal questão, era bastante comum o slogan: "BRASIL-OESTE. Uma revista para agricultores, pecuaristas e homens de negócio".

6 É bom que se diga, no entanto, conforme mostra Célia Regina Jardim Pinto (2003), que o feminismo no Brasil já existia desde as décadas finais do século XIX e passou por inúmeras modificações e vertentes durante o transcorrer do século XX. Naturalmente, isso ocorria também em outras partes do mundo.

7 Apoio-me no conceito de representação tal como articulado por Roger Chartier, pois segundo o autor, é um "precioso apoio para que se pudessem assinalar e articular, sem dúvida, melhor do que nos permitia a noção de mentalidade, as diversas relações que os indivíduos ou os grupos mantêm com o mundo social" (CHARTIER, 2011, p. 20), e nos permite notar/perceber que as "percepções do social não são de forma alguma discursos neutros: produzem estratégias e práticas (...) que tendem a impor uma autoridade à custa de outros, por elas menosprezados, a legitimar um projeto reformador ou a justificar, para os 
próprios indivíduos, as suas escolhas e condutas". Isto significa dizer que as/os historiadoras/ es precisam ficar atentos às lutas que são travadas no campo simbólico, uma vez que elas "têm tanta importância como as lutas econômicas, para compreender os mecanismos pelos quais um grupo impõe, ou tenta impor, a sua concepção de mundo social, os valores que são seus, e o seu domínio." (Chartier, 1990, p. 17).

8 Faço tal afirmação levando em consideração os periódicos catalogados pelo Núcleo de Documentação e Informação Histórica Regional da UFMT (Universidade Federal de Mato Grosso), para maiores detalhes, ver: CALHÃO; MORGADO; MORAES (1994). Tais dados foram confrontados com os obtidos por meio do Anuário de Imprensa Brasileiro e pude constatar que não havia nenhuma revista com direcionamento semelhante à $R B O$ em Mato Grosso no período em apreço.

9 Apenas $1,7 \%$ do total das 164 cartas publicadas pela $R B O$ demonstraram um tom de crítica em relação às suas reportagens.

10 Infelizmente não pude inserir as referidas imagens no presente artigo, pois não consegui autorização.

11 A ortografia foi mantida tal como publicada na versão original.

12 Em nota de rodapé, a autora faz a ressalva de que o trabalho fora do lar, ainda que informal, era muito comum para as mulheres de camadas menos favorecidas economicamente, e que à mulher da classe média, é que era relativamente incomum tal prática. Indico, mais uma vez, que o público da $R B O$ era essencialmente das classes mais abastadas.

13 Tradução nossa. No original: "Definitions of reality were sustained and produced through all those linguistic practices (in the broad sense) by means of which selective definitions of 'the real' were represented. But representation is a very different notion from that of reflection. It implies the active work of selecting, and presenting, of structuring and shaping: not merely the transmitting of an already-existing meaning, but the more active labour of making things mean. It was a practice, a production, of meaning: what subsequently came to be defined as a 'signifying practice'. The media were signifying agents". 
FONTES

\section{Edições utilizadas da revista Brasil-Oeste:}

Revista Brasil-Oeste, $n^{\circ}$ 28, janeiro de 1958.

Revista Brasil-Oeste, n 57, março de 1961.

Revista Brasil-Oeste, $n^{\circ}$ 61, julho de 1961.

Revista Brasil-Oeste, $n^{\circ}$ 78, fevereiro de 1963.

\section{BIBLIOGRAFIA}

ABREU, Alzira A., Imprensa em transição: o jornalismo brasileiro nos anos 50. Rio de Janeiro: Ed. FGV, 1996.

BARBOSA, Marialva História cultural da imprensa: Brasil, 1900-2000. Rio de Janeiro: Mauad Ed., 2007.

BASSANEZI, Carla. Estudos de gênero e história social. Estudos Feministas, Florianópolis, 17 (1): 296, janeiro/abril, 2009.

BASSANEZI, Carla. Revistas femininas e o ideal de felicidade conjugal (19451964). Cadernos Pagu, (1), 1993.

BIASOLI-ALVES, Zélia Maria. Continuidades e Rupturas no Papel da Mulher Brasileira no Século XX. Psicologia: Teoria e Pesquisa. Set-Dez 2000, Vol. 16 n. 3, pp. 233-239.

CALHÃO, Antonio Ernani P.; MORGADO, Eliane Maria O.; MORAES, Sibele. Imprensa periódica mato-grossense: 1847-1969. Cuiabá: Ed. Universitária da UFMT, 1994.

CHARTIER, Roger. A história cultural: entre práticas e representações. Editora Difel: Lisboa, 19901990

CHARTIER, Roger. A ordem dos livros: leitores, autores e bibliotecas na Europa entre os séculos XIV e XVIII. Editora UNB, 2. Ed. 1999

CHARTIER, Roger. Defesa e ilustração da noção de Representação. Fronteiras (UFGD). v. 13, N²4. p. 169-183, 2011. 
CHARTIER, Roger. Diferenças entre os sexos e dominação simbólica (nota crítica). Cadernos Pagu, (4) 1995.

DINIZ, Glaucia; SANTOS, Luciana. Donas de casa: classes diferentes, experiências desiguais. Psicol. clin. vol.23 no.2 Rio de Janeiro 2011.

DINIZ, Gláucia; SANTOS, Luciana. Donas de casa: classes diferentes, experiências desiguais. Revista Psicologia Clínica. Vol. 23, n. 3, Rio de Janeiro, 2011.

FERREIRA, Luzmara C. Prática de leitura: os limites instaurados pela materialidade do suporte de textos revista. 2003. 158f. Dissertação (Mestrado em Letras) - Programa de Pós-Graduação em Letras. UNESP - Araraquara.

HAHNER, J. E. A mulher brasileira e suas lutas sociais e políticas (1850-1937). São Paulo: Brasiliense, 1981.

HALL, Stuart. "The rediscovery of 'ideology': return of the repressed in media studies". In: GUREVITCH, M., BENNET, T., CURRAN, J. e WOOLLACOTT, J. (orgs.), Culture, Society, and the Media, London: Methuen, 1982, p. 56-90.

HEINZ, Flavio. O historiador e as elites - à guisa de introdução. In: HEINZ, Flavio. Por outra história das elites. Rio de Janeiro: FGV, 2006.

LUCA, Tania R. Mulheres em revista. In: PEDRO, Joana Maria; PINSKY, Carla. (Org.). Nova história das mulheres no Brasil. 1ed.São Paulo: Contexto, 2012, v. 1, p. 447-468.

LUCA, Tania R.; MARTINS, Ana L. Imprensa e cidade. São Paulo: UNESP, 2006.

MALUF, Marina; MOTT, Maria Lucia. Recônditos do mundo feminino. IN: NOVAIS, Fernando; SEVCENKO, Nicolau. História da vida privada no Brasil, vol 3. República: da belle époque a era do rádio, 1998.

MARTINS, Ana Luiza. Revistas em Revista: imprensa e práticas culturais em tempos de República, São Paulo (1890-1922). São Paulo: EDUSP, 2008

MORAES, Letícia N. de Góes. A dança efêmera dos leitores missivistas na revista Realidade (1966-1968). 2001. 214f. Dissertação (Mestrado em História). FFLCH/USP, São Paulo.

NUNES, João Arriscado. Um discurso sobre as Ciências 16 anos depois. In: SOUSA SANTOS, Boaventura de (Org.). Conhecimento prudente para uma 
vida decente: um discurso sobre as ciências revisitado. São Paulo: Cortez, 2006.

PASSERINI, Luisa. Mulheres, Consumo e Cultura de Massas. IN: PERROT, Michele e DUBY, Georges. História das mulheres no Ocidente, v. 04. Porto, Portugal: Afrontamento, 2000.

PERROT, Michelle. As mulheres ou os silêncios da história. Bauru, São Paulo: EDUSC, 2005.

PERROT, Michelle. Minha história das mulheres. São Paulo: Contexto, 2007.

PERROT, Michelle. Os excluídos da história: operários, mulheres e prisioneiros. 2a. ed., São Paulo: Paz e Terra, 1992.

PIMENTA, Fabrícia F. A sofisticação teórica da produção relativa à História das Mulheres e aos Estudos de Gênero: Entrevista com Rachel Soihet. Em tempo de Histórias, $n^{\circ}$ 11, 2007.

PINTO, Céli Regina Jardim. Uma história do feminismo no Brasil. São Paulo: Fundação Perseu Abramo, 2003.

RAGO, Margareth. As mulheres na historiografia brasileira. In: SILVA, Zélia Lopes (Org.). Cultura Histórica em Debate. São Paulo: UNESP, 1995.

RAGO, Margareth. Epistemologia Feminista, Gênero e História. PEDRO, Joana Maria; GROSSI, Míriam Pilar (Orgs.). Masculino, Feminino, Plural: gênero na interdisciplinaridade. Florianópolis, SC: Editora Mulheres, 1998.

RIBEIRO, Ana Paula G., Jornalismo, literatura e política: a modernização da imprensa carioca nos anos 1950. Estudos Históricos - CPDOC/ FGV, Rio de Janeiro, v. 31, p. 147-160, 2003.

ROIZ, Diogo da Silva. Linguagem, cultura e conhecimento histórico: ideias, movimentos, obras e autores. Jundiaí:Paco Editorial, 2012.

SCOTT, Joan. Gênero. Categoria útil de análise histórica. Educação e realidade, 20(2): 71-99, jul/dez, 1995. 